\title{
Tools for Empowering Young Learners: Language Learner Autonomy
}

\author{
Che Wan Ida Rahimah bt. Che Wan Ibrahim ${ }^{1}$ \\ ${ }^{1}$ Centre for Liberal and Fundamental Education, Universiti Malaysia Terengganu, Terengganu, Malaysia \\ Correspondence: Che Wan Ida Rahimah bt. Che Wan Ibrahim. E-mail: idaray@umt.edu.my
}

Received: August 2, 2018

Accepted: September 3, 2018

Online Published: January 30, 2019

doi:10.5539/ass.v15n2p1

URL: https://doi.org/10.5539/ass.v15n2p1

\begin{abstract}
This paper critically reviews the potential of social networking tools in the context of informal learning of language for young learners. It provides a synthesis of the research literature in the field that relevant to communities of educators and a series of illustrative examples of how these tools are being used in autonomous language learning. It draws out that the learners are currently turning to the social networking tools for their own, independent language learning. Alongside this, these tools have the potential to greatly enhance the opportunities available for language learners to make meaningful use of their target language in real-time contexts and to develop their productive language skills. For that reason, the use of these tools is a more dynamic approach to language learning, so that the learners gain autonomy and be responsible for their own language learning.
\end{abstract}

Keywords: informal learning, language learning, social media tools, social networking tools, autonomy

\section{Introduction}

Today, the growing popularity of social networking tools has motivated socialisation, critical thinking, and global knowledge sharing and collaborative learning. Accordingly, many researchers have discussed the broad learning benefits of using these technologies in informal learning contexts (Ebner et al., 2009; Greenhow \& Robelia, 2009; McLoughlin, 2018; Lenhart \& Madden, 2007). For example, several hundred social networking tools are platforms "to process knowledge" (Duke, 2010, p. 170) and have potentials in enabling an independent language learning. The following benefits are among those valuable to language learners:

\subsection{Facebook}

One of the most popular social networking tools is Facebook where higher education students are the most frequent users and increasingly spend their time (Carbo \& Antoli, 2011; Dillard, 2011; Eberhardt, 2007; Freishtat, 2009; Lenhart \& Madden, 2007; Schultz, 2011; Selwyn, 2007) "in various forms of informal and self-directed learning outside of formal classroom settings" (Freishtat, 2009, p. 2). As listed on the facebook.com website, Facebook has established itself rapidly since February 2004 and has 500 million active users in the year 2011 (as cited in Schultz, 2011). The main elements of social networking, especially Facebook are as follows:

i) The profile - each user is stimulated to contribute personal details if possible and it "is comprised of identifiers that distinguish one user from another" (Dillard, 2011, p. 2). The profile includes interests, pastimes, e-mail address and preferences in the case of leisure communities (Armstrong \& Franklin, 2008; Eberhardt, 2007; Mills, 2011). After a profile has been verified, new members are able to be in touch with existing members worldwide (macro context) by requesting that members join as their individual (micro context) friend. Learner-users could change their privacy settings to choose the individuals that are able to view their Facebook profile in order to protect their privacy (Dillard, 2011; Freishtat, 2009; Greenhow \& Robelia, 2009).

ii) The network links or list of friends - all members are signified mainly by their contacts or network links starting from real individuals, inviting them to request others including strangers. In this regard, in a Facebook community, "the joint enterprise was participation, engagement, and mutual accountability in a global simulation context" (Mills, 2011, p. 363). A shared practice was developed as users created online profiles for their characters, interacted with co-participants, and posted their shared updates and wall postings on Facebook.

Furthermore, it is clear that Facebook was an important social tool of "popular culture" (Freishtat, 2009) used by the majority of the members especially to aid their transition to University (Armstrong \& Franklin, 2008; Schultz, 
2011). Selwyn's (2007) research on university students' use of one of social networking applications namely Facebook in the UK recommends that the educational nature of students' Facebook use is profoundly casual such as discoveries in corridors, cafeterias and beyond the classroom. Accordingly, due to the convenience and popularity of Facebook usage, users might potentially depend more and more on Facebook, and use it to substitute supplementary forms of interpersonal contact that need extra effort. Thereby, most Facebook members "feel a sense of responsibility to participate on their friends' walls, while others conversely think that their friends should feel that responsibility as well" (Schultz, 2011, p. 35).

In the same vein, Facebook has grown to embrace users' social relationships by enabling learners to maintain their continuing connections with old and new friends. The importance of making new online friendships, intimate friendships and for keeping in touch (Dillard, 2011; Freishtat, 2009; Greenhow \& Robelia, 2009) with friends (or network links) via Facebook is also noticeable. In fact, a challenging representation is developing whereby many users are not simply shifting offline contacts to an online way, or the other way round, but commonly most of them are engaging both at once (Selwyn, 2008). As these connections frequently tolerate physical separation, retaining social networks could aid students to fine-tune existing plans (Eberhardt, 2007; Schultz, 2011) for lifelong learning.

\subsection{Wikis}

Wikis, as defined by Murugesan, are "simple yet powerful Web-based collaborative authoring (or content management) systems for creating and editing content" (Murugesan, 2007, p. 35). Wikis facilitate collaboration and interaction, offer possibilities for immediate feedback, stimulate social connections and communities, and harness knowledge with no associated costs (Boudreaux, 2010; Jonassen et al., 2008; Şahin Kız1l, 2017; Tapscott, 2009). A Wiki is actually a modified web page allowing collaborative individual or group users as active volunteers to add, edit or remove online information at any time and from any location (De Wever, Van Keer, Schellens, \& Valcke, 2011; Jonassen et al., 2008; Murugesan, 2007; Shihab, 2008; Tapscott, 2009). With basic typing skills, it is easy to create content and share information online by adopting available Wiki websites, which may be available publically or accessible only with permission. Today, a Wiki is a tool that enables the collaborative creation of sets of web pages for learner-users and one of the most famous Wikis in the world is Wikipedia an online encyclopaedia (Wikipedia, 2012).

Wikipedia is a free multilingual encyclopaedia, authored by the public (anyone who has an interest in some topic). This largest of Wiki sites was launched in 2001 and has more than 19 million articles, in more than 270 languages, written collectively by volunteers worldwide (Wikipedia, 2012). An increasing number of Wikipedia articles are well-written and informative materials, for example, the 'Featured Articles' and 'Good Articles'. Almost all of its articles can be edited by anyone but in certain cases, Wikis still can support authentication because only certain members can modify certain pages. On a daily basis, hundreds of thousands of global users collectively contribute tens of thousands of edits and publish thousands of their own first-hand articles (Wikipedia, 2012). Tapscott (2009) asserts, "Well, I say that 10,000 heads are better than two. There are a lot of smart people out there, and we should be using new technology to tap into their talent" (p. 91). For instance, the capabilities of wikis to combine, collect and rebuild applications "in intelligent ways to help [learners] make smarter decisions" (Murugesan 2007, p. 37), including Facebook, and Twitter are valuable for language learning. Murugesan (2007) refers a mash-up as "a Web page or Website that combines information and services from multiple sources on the Web" (p. 36). Thus, the users learn more by collaboration in a knowledge-building community in which students are able to develop critical and reflective thinking skills.

Literature also indicates that the use of Wikis as writing dynamic Web applications in education improves writing ideas through collaborative group work (Boudreaux, 2010; De Wever et al., 2011; Jonassen et al., 2008; Şahin Kızıl, 2017). This collective intelligence process of creating a shared object of knowledge where changes of the articles can be tracked to the users directly is noticeably natural in offering great autonomy to the users (Murugesan, 2007). Editors in Wikis communities closely and promptly correct errors when notified. Weinstein et al. (2005) found that the accuracy of Wikis' content was comparable to the Encyclopedia Britannica. Although not without risks in terms of expertise, coverage, volatility of information, Wikis have become very popular for fast and flexible retrieval of information and as tools for evaluative processing and higher order thinking (Weinstein et al.). Wikis can also be used in class projects to save a lot of time for managing group work and instructors can use wikis to supply writing activities (Boudreaux, 2010; Franklin \& Van Harmelen, 2007; Shihab, 2008). It has been suggested that Wikis have educational potentials, especially in the language classroom by utilizing aspects of learners' daily lives and taking advantage of the power of learners guiding other learners (Boudreaux, 2010; De Wever et al., 2011). 
Recently, Woo et al. (2011) proposed that Wikis were helpful in facilitating learners to engage in fun learning and collaborative problem-solving. Those authors further argued that Wikis also facilitated scaffolding learners to achieve their critical-thinking and creative reasoning skills. For instance, the learners post peer comments in order to practice new vocabularies and grammar rules, use online dictionaries, extract main learning ideas from the web, analytically assessing appropriate facts and rehearsing to write better by sharing and observing instances from others. The open mechanism accomplished to help collaboration between learners, and the written conversation online assisted the reluctant or weaker learners with English. For instance, the learners mentioned the ease of editing their work, posting photos and noted that peer interactions encouraged prompt knowledge sharing among group members, such as through repetition and regeneration. Overall, social networking technologies provide resources that motivate learners' plans and encourage engagement in collaborative behaviour where "whatever challenges they encountered, they solved creatively in their own ways" (p. 48).

\subsection{Twitter}

Twitter is an important social networking tool that creates an environment in which users can interact in real and deferred time, thereby accommodating a virtual extension of the physical classroom community (Carbo \& Antoli, 2011; Ebner et al., 2009) by providing an opportunity for membership in the L2 community. Consequently, the tool supports informal learning approaches such as enabling immediate feedback, stimulating information awareness from peer learning activities and monitoring own learning progress (Ebner et al., 2009). This is also the evidence from Antenos-Conforti's study (2009) that investigated the Twitter habits of L2 learners (22 university students) and influenced how they evaluate this tool for learning language and culture. Antenos-Conforti (2009) found that Twitter can transform social networking into educational networking because of its three key features, namely its participatory nature, the authenticity of use and interactivity. Twitter was considered by those users essential for authentic daily language practice because it promoted robust exchanges. Twitter facilitated positive affective choice because while learners tweeted, they felt more relaxed and motivated to converse in L2 (Italian). Some learners remarked that tweeting improved their writing in L2 in terms of grammar and vocabulary. They also acknowledged that their teacher's replies to their tweets benefited their learning and contributed to their knowledge of Italian culture. Overall, Antenos-Conforti (2009) recommended the interactive and dynamic nature of this social networking tool for language teaching and learning.

\subsection{Blogs}

Another social networking application is the use of blogs to promote educational learning goals (Alam \& McLoughlin, 2018; Murray \& Hourigan, 2010; Ngah, 2007). The learner-users can upload their diary entries and, if they wish, publish them. Blogs are an excellent example of web services which incorporate read/write characteristics to foster conversation instead of a non-interactive information broadcast (Murugesan, 2007). In language learning, the blog clearly has high potential for motivating university students, through the exchanging of ideas, and also as a platform for self-directed language learning (Murray \& Hourigan, 2010; Ngah, 2007). Thus, the potential impact of the blogging phenomenon upon teaching and learning contexts reveals an important area for consideration for all university educators (Murray \& Hourigan, 2010; Şahin Kızıl, 2017).

There are some features of blogs that have proven most interesting in this respect. First, blogs are free and are relatively easy to create and update (Murugesan, 2007; Ngah, 2007; Shihab, 2008). Second, most blog software comes with a built-in back end of RSS (Rich Site Summary), which allows readers to easily see when new postings have been made (Murugesan, 2007; Shihab, 2008). This allows users to keep up to date with new content as it is created. RSS feeds offer a great value to language learners feeds, for example, "for getting news feeds, English word of the day, and notifications of new podcasts, blog posts, and Wiki edits" (p. 96). Third, blogs provide links which facilitate other bloggers to connect to individual posts from their posts, which in turn create conversation for socialization and for easy exchange of opinions (Ngah, 2007). At the same time, being able to check their peer's messages, would improve the sense of community (Ullrich et al., 2008). As a result, like other social networking tools, blogs have been identified as the most likely tool for future activities for collaboration purposes. They provide an informal but rich learning source (Ngah, 2007; Shihab, 2008) especially in developing reflective language learning (Murray \& Hourigan, 2010).

Language learners could acquire the target language (TL) at ease and at their own pace through language exploration by participating in blogs if exposed to peer-appropriate L2 conversational proficiency during the learning process. This finding was revealed by Ngah (2007) who explored the correlation between Malaysian students' use of blogs and their language learning. Ngah notes there will be no fear of being corrected by a 
capable person because the initial focus was more on the content rather than the mechanical aspect of language. Therefore, the learners gained initial confidence and critical thinking skills to write in a public space open to comments from others, while adopting roles as contributors and not just consumers of information online (Alam $\&$ McLoughlin, 2018). She further asserts that it is necessary for the learner-users to have access to knowledge in what they are going to write about by applying effective approaches, such as search, read, select, and to think before posting to ensure their writing is worth sharing. Overall, the research notes that blogs have been perceived as an interesting tool for promoting effective language learning by helping students identify the strengths and weaknesses of their writing.

\subsection{YouTube}

The increasing attention paid to YouTube has led to a heightened awareness of and growing interest in individual learning. For instance, Dietel-McLaughlin's study (2010) examined the role played by use of YouTube in the complex connections between democracy and learning. YouTube is a popular video-sharing tool and allows other users to comment on that video content. Dietel-McLaughlin proposes that YouTube emphasizes the community-building and linking application of social networking, as the interactivity of such technologies supports learner-users' interactions within complex networks in order to form communities surrounding shared interests.

YouTube ... offers individuals from across race, ethnic, gender, ability, and class boundaries to view and upload clips that are of interest or significance to them ... The reciprocal relationship between individual and community interests is also seen in the [YouTube] site's consistent. (p. 104)

As a public platform, the tool provides space and opportunity for individuals to discuss social issues around rituals of appropriation, remixing, imitation and other refined approaches of composing. Users also post their own versions of favourite videos as responses to the original, thereby engaging themselves (and other viewers) freely and fully in ways that foster a sense of community within their culture of public sharing. Therefore, the value of YouTube cannot be overstated because learner-users can manipulate YouTube to voice "their private experiences into public view, which holds powerful pedagogical benefits" (p. 133). Thus, YouTube provides ample opportunities for practice in sustaining democratic culture especially for the extension of shared values and problem-solving. Furthermore, every learner is not only able to download complete courses and lectures for personal viewing but also they can make their presence known and their opinions felt by constructing and distributing these via various social networking platforms.

\subsection{Games}

Another growing academic interest is directed towards the learning potential of game-based learning (Feng, 2009; Gee, 2010; Hoy, 2011; Selwyn, 2007, 2008; Wilkerson, 2010). Gaming is argued to offer a range of specific personal language learning opportunities and a highly flexible and engaging social space (Feng, 2009; Gee, 2010; Hoy, 2011; Wilkerson, 2010). In his thesis, Hoy (2011) acknowledges that:

In addition to posing well thought-out and structured problems, games must allow players to practice the skills required to solve these problems until their mastery has become "routinized." Each successive challenge forces players to reconsider their mastery and consolidate it with newly acquired skills through repetition. In this way, players maintain and slowly develop expertise [because language learning] requires repetition and practice to master. (p. 89)

Collaborative networks in gaming can support informal learning in that the "learning in the meaningful context of the game did not occur consciously; rather, it was incidental and incremental" (Feng, 2009, p. 231). Therefore, games are tools for assisting learners to build groups of practice through unlimited problem-solving, repetition, trial and error to construct rules and share knowledge. Indirectly they are perceived to contribute learning cultures (Feng, 2009; Gee, 2010; Hoy, 2011; Selwyn, 2007, 2008; Wilkerson, 2010). For instance, learner-users can decide when and how to spend their time with activities they prefer in focusing certain aspects of language and information exchange (Gee, 2010) or reduce time spent with those they dislike (Hoy, 2011; Wilkerson, 2010). In the long term, this approach increases learner success in autonomous language learning through independent practice (Hoy, 2011, p. 96).

Learner-users' cultural reflection helps them to learn about "ways of life" and "ways of thinking" of native speaking people through the games as self-study tools (Feng, 2009). With different levels of proficiency, distinct roles and goals in mind, they "could personalize their learning experience, focusing on material and aspects of language that help meet their personal goals, academic or communicative" (p. 100). This finding is compatible with Wilkerson's (2010) who claimed that, 
language learning in this environment tends to be highly imaginative and interactive and works well for learners who enjoy tactical and visual sensations. Because learners can digitally touch, move, and build objects that teach them a ... language, they can also see that language skills extend beyond text and speech into creation, of meaning, of space, and of interactions. (p. 134)

\section{Conclusion}

In conclusion, this article has presented an extensive review of the theoretical literature. It fits well into the framework of previous research literature that web tools support learners' autonomy and collaborative learning through the repeated practice and frequent rehearsal towards meaningful engagement, critical thinking, and independent learning cultures. This article also establishes a few important findings from the literature:

(i) As suggested by the literature, web tools offer potential ground for empowering individual personal learning (Şahin Kız1l, 2017; Woo et al., 2011). This, in turn, empowers their perception and valuable activity exploration (Boruta et al., 2011; Gardner, 2011; Mortimer, 2010; Shihab, 2008). Consequently, individual learning is seen to be influenced by the environment and context;

(ii) The interaction within a community and a sense of belonging to a community are important to enable web-based informal language learning. As upheld by sociocultural perspectives (Alam \& McLoughlin, 2018; Dietel-McLaughlin, 2010; Gee, 2010; Mills, 2011), the broader social, cultural and historical context presents the robust frame which influences realistic meaning-making and behaviour during sociocultural interactions in a wider range of educational settings. Thus, when individuals are motivated to learn, it is possible for them to perceive affordances, limitations, and strategies for active learning. Also, it indicates the emergent literature from data analysis as a confirmation and validation of the knowledge area;

(iii) Demonstrated how new interactive technologies are vital aspects of transformation that need to transpire in learning beyond the classroom for risk-free practice.

\section{Acknowledgements}

The author is grateful for the constructive comments of the colleagues from Universiti Malaysia Terengganu on an earlier version of this paper. The author was supported by Universiti Malaysia Terengganu and Ministry of Higher Education Malaysia.

\section{References}

Alam, S. L., \& McLoughlin, C. (2018). E-Citizenship Skills Online: A Case Study of Faculty Use of Web 2.0 Tools to Increase Active Participation and Learning. In Information and Technology Literacy: Concepts, Methodologies, Tools, and Applications (pp. 878-896). IGI Global.

Antenos-Conforti, E. (2009). Microblogging on Twitter: Social networking in intermediate Italian classes. In L. Lomicka, \& G. Lord (Eds.). The next generation: Social networking and online collaboration in foreign language learning (pp. 59-90). San Marcos, TX: CALICO.

Armstrong, J., \& Franklin, T. (2008). A review of current and developing international practice in the use of social networking (Web 2.0) in higher education. Retrieved from http://www.franklinconsulting.co.uk/ LinkedDocuments/the\%20use\%20of\%20social\%20networking\%20in\%20HE.pdf

Boudreaux, M. (2010). Collaboration via Wikis: Social aspects and adapting teacher feedback in an online environment (Master's thesis, University of Louisiana). Retrieved from http://etd.lsu.edu/docs/available/ etd11182010131545/unrestricted/BoudreauxThesis.pdf

Carbó, A. R., \& Antolí, N. S. (2011). Online students initiate informal learning practices using social tools. ELearning Papers. Retrieved from http://www.elearningeuropa.info/en/article/Online-students-initiateinformallearningpractices-using-social-tools

De Wever, B., Van Keer, H., Schellens, T., \& Valcke, M. (2011). Assessing collaboration in a wiki: The reliability of university students' peer assessment. Internet and Higher Education, 14(4), 201-206. https://doi.org/10.1016/j.iheduc.2011.07.003

Dietel-McLaughlin, E. (2010). Remediating democracy: YouTube and the vernacular rhetorics of Web 2.0. (Doctoral Dissertation). Retrieved from ProQuest Dissertations and Theses database. (UMI No. 3417839)

Dillard, T. E. (2011). Privacy and security implications of undergraduate students using Facebook: A quantitative examination (Doctoral Dissertation). Retrieved from ProQuest Dissertations and Theses database. (UMI No. 3449100)

Duke, R. A. (2010). Students' learning experiences with the Web 2.0 Tool MyPortfolio: A case study of one high 
school classroom (Master's thesis, Victoria University of Wellington, New Zealand). Retrieved from http://researcharchive.vuw.ac.nz/handle/10063/1302

Eberhardt, D. M. (2007). Facing up to Facebook. About Campus, 12(4), 18-26. https://doi.org/10.1002/abc.219

Ebner, M., Lienhardt, C., Rohs, M., \& Meyer, I. (2009). Microblogs in Higher Education - A chance to facilitate informal and process-oriented learning? Computers \& Education, 55(1), 92-100. https://doi.org/10.1016/j.compedu.2009.12.006

Feng, L. (2009). How do adult foreign language learners experience the opportunities presented by computer games as a self-study tool? (Doctoral Dissertation). Retrieved from ProQuest Dissertations and Theses database. (UMI No.3357576)

Franklin, T., \& Van Harmelen, M. (2007). Web 2.0 for content for learning and teaching in higher education. Retrieved from http://ie-repository.jisc.ac.uk/148/1/web2-content-learning-and-teaching.pdf

Freishtat, R. L. (2009). Learning in the technological frontier: Facebooks public pedagogy and experiences with digital curriculum (Doctoral Dissertation). Retrieved from ProQuest Dissertations and Theses database. (UMI No. 3380662)

Gee, J. P. (2010). New digital media and learning as an emerging area and "worked examples" as one way forward. Cambridge, Mass: The MIT Press.

Greenhow, C., \& Robelia, B. (2009). Informal learning and identity formation in online social networks. Learning, Media and Technology, 34(2), 119-140. https://doi.org/10.1080/17439880902923580

Hoy, T. E. (2011). There's an App for That: Foreign Language Learning through Mobile and Social Media-Based Video Games (Master's thesis, University of Tennessee). Retrieved from http://trace.tennessee.edu/utk_gradthes/883

Jonassen, D. H., Howland, J., Marra, R. M., \& Crismond, D. P. (2008). Meaningful learning with technology (3rd ed.). Upper Saddle River, NJ: Pearson/Merrill Prentice Hall.

Lenhart, A., \& Madden, M. (2007). Teens, privacy, \& online social networks. Pew Internet and American Life Project Report. Retrieved from http://www.pewinternet.org/ /media/Files/Reports/2007/PIP_Teens Privacy_SNS_eport_Final.pdf.pdf

Mills, N. (2011). Situated learning through social networking enterprise, mutual engagement, and a shared repertoire. CALICO Journal, 28(2), 345-368. https://doi.org/10.11139/cj.28.2.345-368

Murray, L., \& Hourigan, T. (2010). Using blogs to help language students to develop reflective learning strategies: Towards a pedagogical framework. Australasian Journal of Educational Technology, 26(2), 209-225. Retrieved from http://www.ascilite.org.au/ajet/ajet26/hourigan.pdf

Murugesan, S. (2007). Understanding Web 2.0. IT Professional Magazine, 9(4), 34-41. https://doi.org/10.1109/MITP.2007.78

Ngah, E. (2007). Blog-based online journals for English as second Language learners (Master's thesis, Univ. Technology of Malaysia). Retrieved from http://eprints.utm.my/6524/1/EzihaslindaNgahMFP.pdf

Şahin Kızıl, A. (2017). EFL learners in the digital age: An investigation into personal and educational digital engagement. RELC Journal, 48(3), 373-388. https://doi.org/10.1177/0033688216684285

Schultz, K. T. (2011). Friends on Facebook: The impact of Facebook on interpersonal friendships of female college students (Master's thesis, Gonzaga University). Retrieved from http://search.proquest.com/docview/ 914706703? accountid $=12001$

Selwyn, N. (2007). Citizenship, Technology and Learning: A review of recent literature. Bristol, Futurelab. Retrieved from http://archive.futurelab.org.uk/resources/documents/lit_reviews/Citizenship_Review_update. pdf

Shihab, M. M. (2008). Web 2.0 tools improve teaching and collaboration in high school English language classes (Doctoral Dissertation). Retrieved from ProQuest Dissertations and Theses database. (UMI No. 3344829)

Tapscott, D. (2009). Grown up Digital: How the net generation is changing our world. New York: McGraw-Hill Professional.

Ullrich, C., Borau, K., Luo, H., Tan, X., Shen, L., \& Shen, R. (2008). Why Web 2.0 is good for learning and for research: Principles and prototypes. Paper presented at the Proceedings of the 17th International World 
Wide Web, New York. Retrieved from http:/halshs.archives-ouvertes.fr/docs/00/58/87/57/PDF/ULLRICHCARSTEN-2008.pdf

Weinstein, L., Denning, P., Horning, J., \& Parnas, D. (2005). Wikipedia Risks. Communications of the ACM (CACM), 48(12), 152. https://doi.org/10.1145/1101779.1101804

Wikipedia. (2012). Wikipedia, the free encyclopedia. Retrieved from http://en.wikipedia.org/wiki/Main_Page

Wilkerson, A. (2010). Electrate language learning: An analysis of foreign language acquisition in virtual environments (Master's thesis). Available from ProQuest Dissertations and Theses database. (UMI No. 1475591)

Woo, M., Chu, S., Ho, A., \& Li, X. (2011). Using a Wiki to Scaffold Primary-School Students' Collaborative Writing. Educational technology \& society, 14(1), 43-54. Retrieved from http://www.ifets.info/journals/14_1/5.pdf

\section{Copyrights}

Copyright for this article is retained by the author(s), with first publication rights granted to the journal.

This is an open-access article distributed under the terms and conditions of the Creative Commons Attribution license (http://creativecommons.org/licenses/by/4.0/). 